\title{
Comunicación
}

\section{Nefrocalcinosis intersticial y glomerulonefritis crónica en una perra}

\author{
INTERSTITIAL NEPHROCALCINOSIS AND CHRONIC GLOMERULONEPHRITIS IN A BITCH
}

\author{
Jacqueline Cahua U. ${ }^{1,3}$, Rosa Perales C. ${ }^{2}$
}

\section{Resumen}

La nefrocalcinosis difusa es una condición rara en perros. Se reporta el caso de una perra mestiza de un año, que presentaba una falla renal crónica severa, y que al estudio ecográfico se observó una mineralización difusa bilateral renal. El diagnóstico histopatológico fue una severa glomerulonefritis no supurativa difusa crónica con calcificación metastásica y atrofia tubular.

Palabras clave: nefrocalcinosis intersticial; glomerulonefritis; perro; ecografía; riñón

\section{Abstract}

Diffuse nephrocalcinosis is a rare condition in dogs. It is reported the case of a one-year-old crossbred female dog with severe chronic renal failure, and bilateral diffuse renal mineralization detected by ultrasound. The histopathological diagnosis was a severe diffuse non-suppurative chronic glomerulonephritis with metastatic calcification and tubular atrophy.

Key words: interstitial nephrocalcinosis; glomerulonephritis; dog; ultrasound; kidney

${ }^{1}$ Clinica de Animales Menores, Facultad de Medicina Veterinaria, Universidad Nacional Mayor de San Marcos, Lima, Perú

${ }^{2}$ Laboratorio de Histología, Embriología y Patología Veterinaria, Facultad de Medicina Veterinaria, Universidad Nacional Mayor de San Marcos, Lima, Perú

${ }^{3}$ E-mail:jcahuau@unmsm.edu.pe

Recibido: 12 de febrero de 2018

Aceptado para publicación: 8 de mayo de 2018 
INTRODUCCIÓN

La nefrocalcinosis se refiere a depósitos de calcio en el parénquima renal, reservándose la denominación de calcificaciones para el hallazgo histopatológico en los tejidos y de litiasis para acumulaciones en la vía urinaria, visualizándose por medios radiológicos y ecográficos, dando imágenes que pueden ser focales o difusas y que comprometen la corteza, la papila o ambas. La localización de las calcificaciones se relaciona con determinadas enfermedades y puede ser un signo de ayuda para el diagnóstico etiológico (Puga et al., 1987; Corbetta et al., 2005; Aragonez et al., 2011).

La nefrocalcinosis puede encontrarse asociada a hipercalcemia, normocalcemia e hipercalciuria, así como con urolitiasis, con la que frecuentemente coinciden sus factores predisponentes (Puga et al., 1987; Dimkovic y Wallele, 2002). Las manifestaciones clínicas dependen de la causa de la nefrocalcinosis, ya que puede ser asintomática y ser un hallazgo incidental, durante el estudio radiológico o ecográfico (Puga et al., 1987; Corbetta et al., 2005). Los depósitos de calcio en la forma metastásica se depositan en tejidos sanos con o sin hipercalcemia. Estos depósitos se localizan con mayor frecuencia en los riñones, pulmón y mucosa gástrica, lo que sugiere que la precipitación del calcio, en estados de hipercalcemia, se ve favorecida en lugares donde se elimina ácido (Puga et al., 1987; Talavera, 2010).

En este artículo se describe el caso de un paciente con nefrocalcinosis, diagnosticado inicialmente mediante ecografía.

\section{Caso Clínico}

\section{Evaluación del Paciente}

Canino hembra de raza mestiza de 1 año, $8.7 \mathrm{~kg}$ de peso, condición corporal 2/5. Fue llevada a un consultorio particular en la ciu- dad de Lima con signos de polidipsia e inapetencia durante tres semanas, así como vómitos y anorexia por tres días. Presentaba marcados signos de deshidratación.

Los resultados del examen hematológico fueron: hematocrito $50 \%$, eritrocitos $8.2 \times 10^{6} / \mu 1$, leucocitos $21.1 \times 10^{3} / \mu 1$, con leve desviación a la izquierda, plaquetas $1.5 \times 10^{5} / \mu 1$, alanino aminotransferasa (ALT) $86.3 \mu / 1$, proteínas totales $4.7 \mathrm{~g} / \mathrm{dl}$, albumina $2 \mathrm{~g} / \mathrm{dl}$, bilirrubina normal, nitrógeno ureico (BUN) $120.4 \mathrm{mg} / \mathrm{dl}$, urea 257.6 , creatinina $5.5 \mathrm{mg} / \mathrm{dl}$ y glucosa $98.8 \mathrm{mg} / \mathrm{dl}$.

Al examen ecográfico abdominal se observaron los riñones de bordes lisos, donde todo el parénquima producía una fuerte sombra acústica. El riñón derecho medía $53 \mathrm{~mm}$ de longitud y $27 \mathrm{mmm}$ de transverso y el riñón izquierdo $53 \mathrm{~mm}$ de longitud y $28 \mathrm{~mm}$ de transverso (Figura 1). Presentaba además signos de enteritis. El hígado y el bazo presentaban parénquima y tamaño conservados. El diagnóstico inicial fue de calcificación renal difusa bilateral. Para corroborar el hallazgo se realizó un examen radiológico, donde se pudo observar la mineralización difusa en todo el parénquima renal (Figura 2).

Los propietarios decidieron por el sacrificio del animal. En la necropsia se observaron los riñones congestionados, de bordes lisos (Figura 2) con disminución del área cortical y congestión medular. Al corte se sentía como arena en todo el parénquima. Los intestinos levemente congestionados, mucosa gástrica conservada y contenido gástrico líquido verdoso.

En el estudio histopatológico de los riñones se pudo observar en la corteza la dilatación del espacio glomerular, en el interior de algunos espacios se encontró sustancia acidófila (material proteináceo). El pelotón glomerular se apreciaba dilatado, comprimido o ausente (Figura 3), y la cápsula de Bowman engrosada con material basófilo de bordes cortantes. Este material también se encuentró en la membrana basal de los 

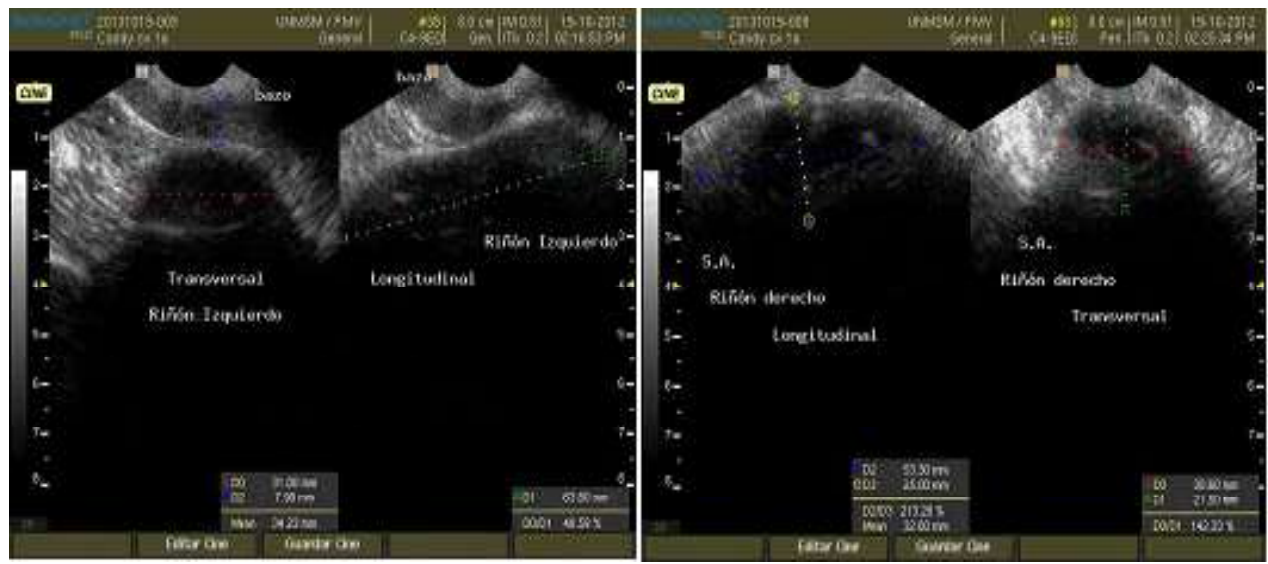

Figura 1. Imágenes ecográficas del riñón izquierdo y derecho, donde se observa una sombra acústica difusa que proviene de todo el parénquima renal, permitiendo observar parcialmente el parénquima con dificultad
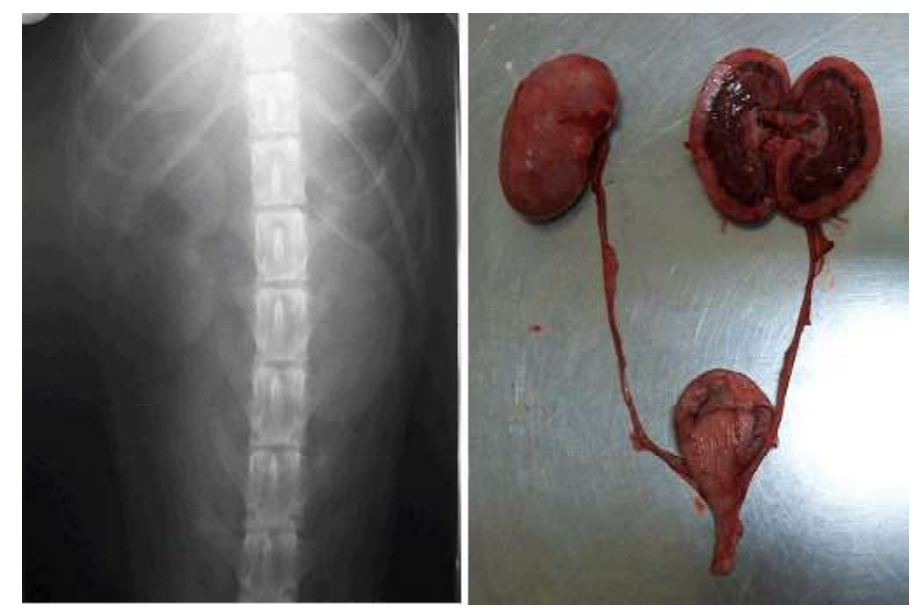

Figura 2. Lado izquierdo: Radiografía mostrando nefrocalcinosis bilateral. Se observa una marcada radiopacidad de los riñones. Lado derecho: Riñones. Obsérvese el borde liso, con disminución del área cortical y congestión medular

túbulos proximales y en mayor cantidad en la zona cercana a la médula, resultando positivo a calcio con la coloración Von Kossa (Figura 4).

A nivel cortical y medular se observó una disminución de túbulos renales, algunos de los cuales presentan una descamación del epitelio de los túbulos proximales. Algunas células se observaron tumefactas y con pérdida del detalle celular. A nivel de la mem- brana basal se observó el mismo material basófilo descrito en la cápsula de Bowman. Además, presentaba un incremento del tejido conectivo intersticial, sobre todo a nivel medular, con presencia de células inflamatorias mononucleares, predominantemente linfocitos, y depósitos de calcio en los túbulos distales (Figura 5). El diagnóstico histopatológico fue severa glomerulonefritis no supurativa difusa crónica con calcificación metastásica y atrofia tubular. 


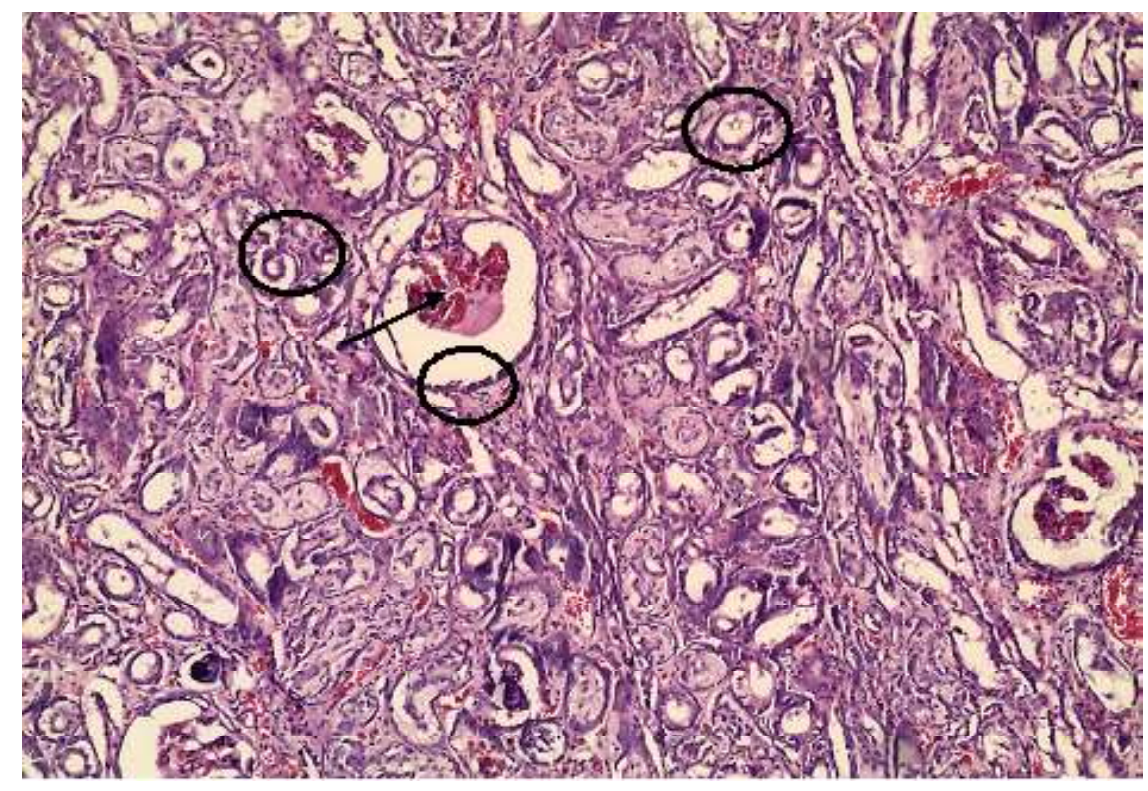

Figura 3. Se observa dilatación de espacio glomerular con sustancia acidófila en su interior (flecha), cápsula de Bowman y membrana basal de los túbulos con material basófilo de bordes cortantes compatible con calcio. 100X, H-E

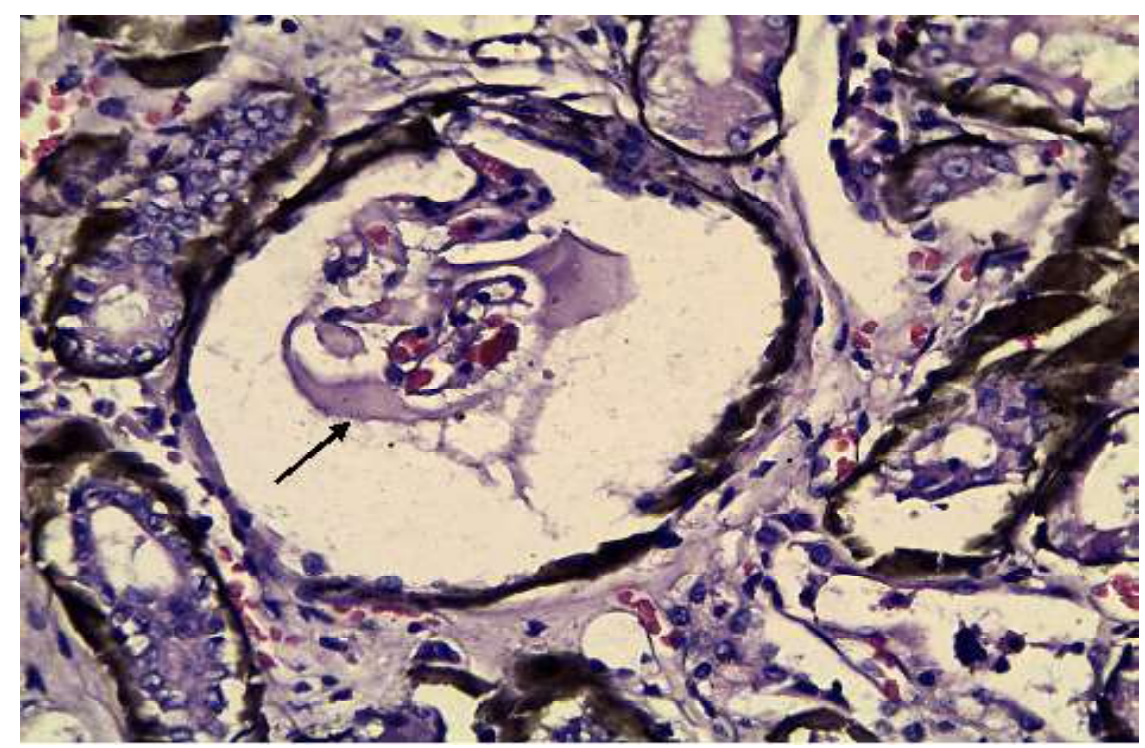

Figura 4. Se observa dilatación de espacio glomerular con sustancia acidófila en su interior (flecha), cápsula de Bowman y membrana basal de los túbulos de color oscuro, positivo a depósito de calcio. 400X, Von Kossa 


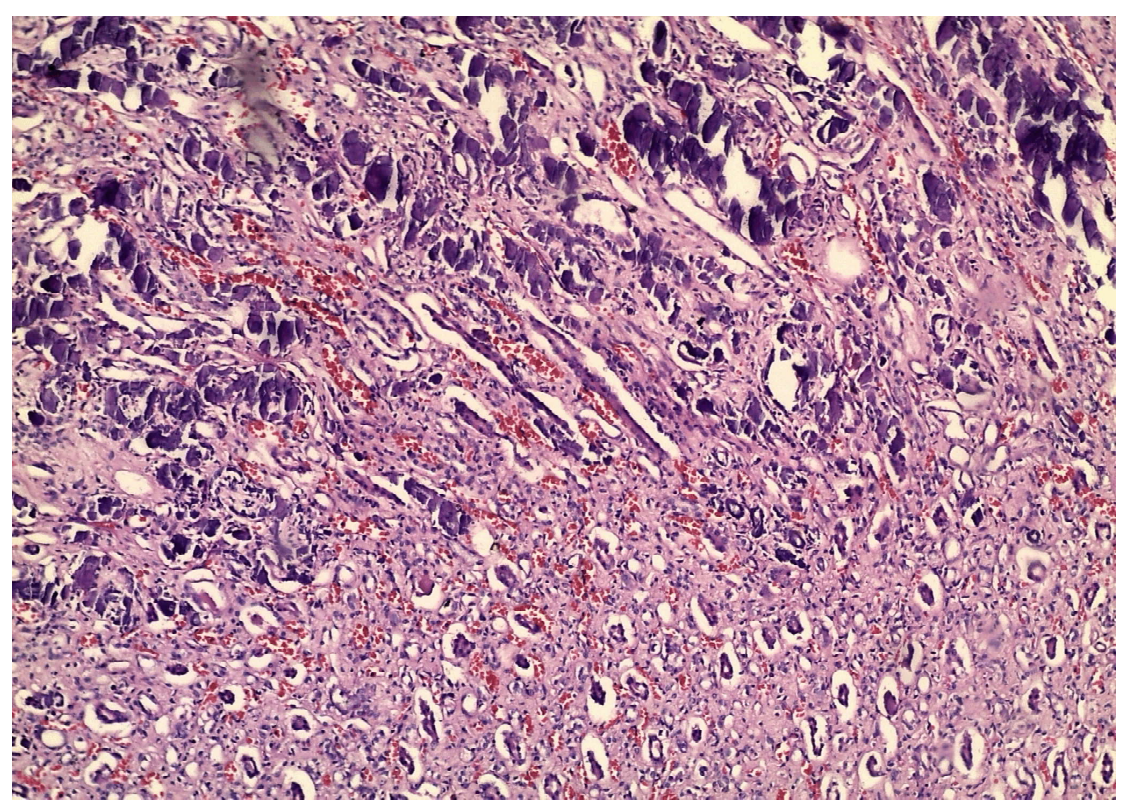

Figura 5. Zona medular con incremento de conectivo intersticial, depósitos de material basófilo de bordes cortantes en los túbulos, compatible con depósitos de calcio. 100X, H-E

\section{Discusión}

La nefrocalcinosis metastásica se produce en hipercalcemia secundaria a hiperparatiroidismo, insuficiencia renal o acidosis tubular renal (Dimkovic y Wallele, 2002). En humanos, solo el $5 \%$ de las nefrocalcinosis afecta la zona cortical. Las causas más frecuentes de nefrocalcinosis cortical son la glomerulonefritis crónica, la hipercalcemia crónica, la necrosis cortical aguda y el rechazo crónico del trasplante renal (Harris et al., 1980; Wrong, 1998; Arons et al., 1995; Schepens et al., 2000). La necrosis cortical es una de las causas más comunes de nefrocalcinosis cortical, observándose en casos de sepsis, deshidratación severa, hemorragias, isquemia renal y mordedura de serpientes (Ferreira et al., 2017). En la nefrocalcinosis cortical, la calcificación se presenta como puntos o como un anillo delgado delineando la corteza (Dyer et al., 1998).
En el presente caso, la paciente presentaba una glomerulonefritis crónica confirmada por histopatología, con depósitos de calcificación intersticial a nivel cortical y medular, principalmente en la zona corticomedular. El estudio ecográfico evidenció los microfocos difusos de sombra acústica causadas por la calcificación desde la superficie cortical, y en todo el parénquima renal, de semejante intensidad en ambos riñones, que se pudo corroborar con el estudio radiológico, donde se observó una radiopacidad difusa en ambos riñones.

En las insuficiencias renales se produce una acidosis metabólica, debido a la acumulación de los metabolitos que producen las células y por el catabolismo de los alimentos ingeridos. El riñón normal mantiene el equilibrio acido-base sanguíneo mediante la filtración y la reabsorción de todo el bicarbonato, la síntesis de amonio y bicarbonato y la excreción de los ácidos (Escobar et al., 2013). 
En humanos se presenta una enfermedad congénita en niños que es la acidosis tubular renal distal, donde el riñón pierde su capacidad de acidificar la orina por un defecto en la excreción de la carga ácida. En estos casos se observa en la ecografía una nefrocalcinosis y/o una nefrolitiasis (Escobar et al., 2013). En el presente reporte, el paciente canino era un animal joven ( 1 año), que pudo haber padecido una infección renal que produjo las lesiones renales crónicas que permitieron la precipitación de calcio o haber sufrido de una acidosis tubular renal distal congénita que acidificó el parénquima renal. Se ha demostrado que los fibroblastos pueden producir mediadores inflamatorios que precipitan iones de calcio y cristales de oxalato (Vervaet et al., 2009).

Se ha observado nefrocalcinosis intersticial en ratones, de forma experimental, debido a la falta genética de moduladores de cristalización como las proteínas TammHorsfall y osteopontina (fosfato de calcio), y en mayor cantidad cuando fueron inducidos por la administración de vitamina D3 y etilenglicol (Khan, 2010). Esto sugeriría que un defecto genético en la formación de inhibidores de cristalización a nivel de túbulos renales no necesariamente se manifestaría con una calcinosis intersticial difusa, a menos que tenga un factor predisponente. En el presente caso, la paciente presentaba una severa glomerulonefritis crónica y atrofia tubular, que la llevó a una acidosis metabólica.

La hipercalcemia favorece la precipitación de calcio en los tejidos renales, siendo sus causas el hiperparatiroidismo primario, hipertiroidismo hipercálcico, intoxicación por vitamina $\mathrm{D}$, hipercalciuria idiopática (Rodriguez, 2002; Rejnmark et al., 2011). Nagode y Chew (1992) manifiestan que la nefrocalcinosis en perros se debe principalmente al exceso de la hormona paratiroidea producida en la enfermedad renal. Debido a que la paciente fue sacrificada no se le pudo hacer estudios para confirmar estas teorías.
En humanos existe la hipercalcemia hipocalciúrica familiar que es de carácter hereditario (Moe, 2008). Se reporta también nefrocalcinosis en recién nacidos prematuros, asociado al tratamiento de furosemida (Karlowicz et al., 1993). En perros no se han reportado enfermedades hereditarias que produzcan hipercalcemia. Este es un caso inusual de nefrocalcinosis en un animal joven, debido a que la distribución de precipitado cálcico era intersticial, difuso y abundante en corteza y médula renal en un animal joven con nefropatía crónica. Este sería un primer reporte en perros de una enfermedad hereditaria que produzca hipercalcemia.

\section{Literatura Citada}

1. Aragonés M, Parra ML, Cigüenza M, Medina M, Peláez D. 2011. Calcificaciones renales: imagen en ecografía. EuroEco 2(2): 68-71.

2. Arons WL, Christensen WR, Sosman MC. 1955. Nephrocalcinosis visible by X-ray associated with chronic glomerulonephritis. Ann Intern Med. 42: 260-282.

3. Corbetta S, Baccarelli A, Aroldi A, Vicentini L, Fogazzi GB, EllerVainicher C. 2005. Risk factors associated to kidney stones in primary hyperparathyroidism. J Endocrinol Inv 28: 122-128.

4. Dimkovic NB, Wallele AA, Oreopoulos DG. 2002. Renal stone disease, elevated iPTH level and normocalcemia. Int Urol Nephrol 34: 135-141.

5. Dyer R, Chen M, Zagoria R. 1998. Abnormal calcifications in the urinary tract. Radiographics 18: 1405-1424. doi: 10.1148/radiographics. 18.6.9821191

6. Escobar L, Mejía N, Gil H, Santos F. 2013. La acidosis tubular renal distal: una enfermedad hereditaria en la que no se pueden eliminar los hidrogeniones. Nefrología 33: 289-296. 
7. Ferreira A, Ferreira $N$, Leitão $J$, Fonseca-Santos J. 2017. Cortical nephrocalcinosis asymmetrically involving the kidneys: a case report documenting the development via imaging. Port J Nephrol Hypert 31: 300-3045.

8. Harris L, Cohen E, Kassner G, Haller JO. 1980. Nephrocalcinosis in chronic glomerulonephritis: report of the youngest patient. Urol Radiol 2: 51-52.

9. Karlowicz M, Katz M, Adelman R, Solhaug M. 1993. Nephrocalcinosis in very low birth weight neonates: family history of kidney stones and ethnicity as independent risk factors. J Pediatr 122: 635-638. doi: 10.1016/S0022-3476(05) 83553-X

10. Khan SR. 2010. Nephrocalcinosis in animal models with and without stones. Urol Res 38: 429-438. doi: 10.1007/s00240010-0303-4

11. Moe S. 2008. Disorders involving calcium, phosphorus, and magnesium. Prim Care 35: 215-vi. doi: 10.1016/ j.pop.2008.01.007

12. Nagode L, Chew D. 1992. Nephrocalcinosis caused by hyperparathyroidism in progression of renal failure: treatment with calcitriol. Semin Vet Med Surg 7: 202-220.
13. Puga F, Bahamondes A, Poniachik J. 1987. Nefrocalcinosis. Rev Chil Pediatr 58:397-401.

14. Rejnmark L, Vestergaard P, Mosekilde L. 2011. Nephrolithiasis and renal calcifications in primary hyperparathyroidism. J Clin Endocrinol Metab 96: 2377-2385. doi: 10.1210/jc.2011-0569

15. Rodriguez J. 2002. Renal tubular acidosis: the clinical entity. J Am Soc Nephrol 13: 2160-2170. doi: 10.1097/ 01.ASN.0000023430.92674.E5

16. Schepens D, Verswijvel G, Kuypers D, Vanrenterghem $Y$. 2000. Renal cortical nephrocalcinosis. Nephrol Dial Transplant 15: 1080-1082.

17. Talavera J. 2010. Síndrome urémico. En: Cortadellas O (ed). Manual de nefrología y urología clínica canina y felina. España: SERVET. p 35-46.

18. Vervaet B, Verhulst A, D'Haese P, De Broe M. 2009. Nephrocalcinosis: new insights into mechanisms and consequences. Nephrol Dial Transplant 24: 2030-2035. doi: 10.1093/ndt/gfp115

19. Wrong O. 1998. Nephrocalcinosis. In: Cameron S (ed). Oxford textbook of clinical nephrology. New York: Oxford University Press. p 1380-1381. 